\title{
Studies of the small bowel surface by scanning electron microscopy in infants with persistent diarrhea
}

U. Fagundes-Neto ${ }^{1}$, S. De Martini-Costa ${ }^{1}$, M.Z. Pedroso ${ }^{1}$ and I.C.A. Scaletsky²

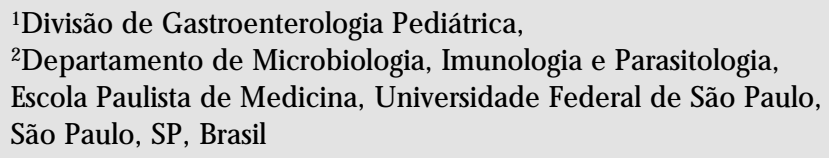

'Divisão de Gastroenterologia Pediátrica, 2Departamento de Microbiologia, Imunologia e Parasitologia, Escola Paulista de Medicina, Universidade Federal de São Paulo, São Paulo, SP, Brasil

\section{Correspondence \\ $U$. Fagundes-Neto \\ Av. Cons. Rodrigues Alves, 1239 \\ 04014-012 São Paulo, SP \\ Brasil \\ Fax: +55-11-570-2613}

Research supported by CN Pq. Publication supported by FAPESP

Received December 21, 1999 Accepted August 30, 2000

\section{Abstract}

We describe the ultrastructural abnormalities of the small bowel surface in 16 infants with persistent diarrhea. The age range of the patients was 2 to 10 months, mean 4.8 months. All patients had diarrhea lasting 14 or more days. Bacterial overgrowth of the colonic microflora in the jejunal secretion, at concentrations above $10^{4}$ colonies/ml, was present in $11(68.7 \%)$ patients. The stool culture was positive for an enteropathogenic agent in $8(50.0 \%)$ patients: for EPEC O111 in 2, EPEC O119 in 1, EAEC in 1, and Shigella flexneri in 1; mixed infections due to EPEC O111 and EAEC in 1 patient, EPEC O119 and EAEC in 1 and EPEC O55, EPEC O111, EAEC and Shigella sonnei in 1. Morphological abnormalities in the small bowel mucosa were observed in all 16 patients, varying in intensity from moderate $9(56.3 \%)$ to severe $7(43.7 \%)$. The scanning electron microscopic study of small bowel biopsies from these subjects showed several surface abnormalities. At low magnification (100X) most of the villi showed mild to moderate stunting, but on several occasions there was subtotal villus atrophy. At higher magnification $(7,500 \mathrm{X})$ photomicrographs showed derangement of the enterocytes; on several occasions the cell borders were not clearly defined and very often microvilli were decreased in number and height; in some areas there was a total disappearance of the microvilli. In half of the patients a mucus-fibrinoid pseudomembrane was seen partially coating the enterocytes, a finding that provides additional information on the pathophysiology of persistent diarrhea.

\section{Introduction}

Persistent diarrhea of presumably infectious etiology is responsible for approximately half of the $3,300,000$ yearly deaths It is assumed that 3 to $23 \%$ of the acute diarrhea episodes evolve to persistence and are also associated with adverse effects on growth and nutrition (3). due to diarrhea in developing countries $(1,2)$.

\section{Key words}

- Persistent diarrhea

- Small bowel

- Scanning electron microscopy

- Bacterial proliferation

- Infants
The etiologic and pathophysiologic factors of persistent diarrhea have not been clearly established. Small bowel lesions described in infants with persistent diarrhea may be due to several noxious factors, namely, nutritional deficiencies $(4,5)$, direct action of some enteropathogenic agents on the enterocyte (6), food allergy (7), acting separately or in an associated fashion. Light microscopy studies of the small bowel mucosa have fre- 
quently shown different degrees of villus atrophy, including subtotal villus atrophy, with increased inflammatory infiltrate in the lamina propria $(8,9)$. Moreover, ultrastructural derangements of the enterocyte and organelles have been reported in studies with the transmission electron microscope (10). However, there are few studies available in the literature describing surface aspects of the enterocytes using scanning electron microscopy in children with chronic diarrhea due to food allergy and giardiasis $(11,12)$. The most frequent abnormalities observed in these reports were an excessive production of mucus, loss of the glycocalyx and the presence of a pseudomembrane covering the epithelial surface.

The present study was designed to describe the ultrastructural abnormalities of the small bowel surface in infants with persistent diarrhea. The study was approved by the Research and Ethics Committee of Escola Paulista de Medicina, and informed consent was granted by the parents.

\section{Patients and Methods}

\section{Patients}

Sixteen infants consecutively admitted to the Diarrhea Unit of São Paulo Hospital, São Paulo, SP, Brazil, with persistent diarrhea were studied. The age range of the patients was 2 to 10 months, mean 4.8 months. Diarrhea was defined as 3 or more liquid stools per day, representing a change from the previous bowel pattern. Persistent diarrhea was characterized as a diarrheic syndrome, presumably of infectious etiology, lasting 14 or more days, with significant impairment of nutritional status (1).

Patient nutritional status was evaluated utilizing the Goméz criteria (13) and the NCHS growth chart as reference (14).

During hospitalization, after correction of the electrolyte imbalance and when the patients had overcome the critical phase, they were submitted to pertinent investigation.

\section{Stool culture and rotavirus test}

Stool specimens were collected upon admission and examined for the usual enteric pathogens (EP) (diarrheogenic Escherichia coli (EC), Salmonella, Shigella, Yersinia enterocolitica, Campylobacter, Cryptosporidium, and ova and parasites) using standard techniques (15). Three to five colonies biochemically identified as E. coli were serotyped according to standard methods, using commercially available polyvalent and monovalent sera (Probac do Brasil, São Paulo, SP, Brazil) against $O$ antigens of EPEC, enteroinvasive (EIEC), or O157 enterohemorrhagic (EHEC) serogroups of $E$. coli (16). Detection of enterotoxigenic $E$. coli (ETEC) and enteroaggregative E. coli (EAEC) was performed by hybridization with the heat-labile and heat-stable enterotoxin DNA probes (LT I, LT II, STh) and AA probe, respectively (17). Rotavirus antigen was identified by an enzyme-linked immunoassay (18).

\section{Small intestinal biopsy and jejunal secretion culture}

The 16 patients were intubated via the nasogastric route by the technique of Toccalino and O'Donnell (19), using a flexible radio-opaque polyethylene tube distally coupled to a 1.6-mm twin port Watson intestinal capsule. The course of the capsule was followed by fluoroscopy to the Treitz flexure. When the capsule reached this region, jejunal secretion was carefully aspirated with a 2.5 -ml syringe. The first $0.5 \mathrm{ml}$ of secretion was discarded, and the next $0.5-1.0 \mathrm{ml}$ was obtained for bacterial culture. The presence of bacterial counts of more than $10^{4}$ colonies/ml was considered compatible with bacterial overgrowth of the small bowel. The bacteria were isolated and identified in all cases. Once secretion was collected, the cap- 
sule was fired and one fragment of jejunum thus obtained was fixed in buffered formalin for light microscopy evaluation. The preparation was stained with hematoxylin and eosin, and biopsies were interpreted according to the criteria of Schenk and Klipstein (20). The other fragment was immediately fixed in $2.5 \%$ glutaraldehyde buffered with $0.1 \mathrm{M}$ sodium cacodylate buffer, $\mathrm{pH} 7.2$, for scanning electron microscopy evaluation. After gentle washing in buffer, so as not to remove surface mucus, the tissue was postfixed in $1 \%$ osmium tetroxide, dehydrated through an ethanol series and dried in a CPD 030 critical point dryer. Subsequently specimens were attached to 0.5 -inch aluminum stubs and coated with silver colloid (Silver Print). Biopsies were examined with a JEOL JSM 5300 scanning microscope at low, medium and high power.

\section{Rectal biopsy}

Rectal mucosa specimens were obtained with a 1.8-mm port size Rubin multipurpose suction biopsy instrument. Biopsy specimens were fixed in $10 \%$ formalin and stained with hematoxylin and eosin for light microscopy evaluation. Morphological interpretation was based on the Goldman and Proujansky criteria (21).

\section{Results}

All patients had some degree of proteincalorie malnutrition (PCM), as follows: 5 were PCM I, 7 PCM II and 4 PCM III (13).

The results of laboratory investigation of our patients are shown in Table 1. Bacterial overgrowth of the colonic microflora in the jejunal secretion at concentration above $10^{4}$ colonies/ml was present in 11/16 (68.7\%) patients. Stool culture was positive for an enteropathogenic agent in $8(50.0 \%)$ of them. In 3 , the same enteropathogenic bacteria were isolated from the stools and from the jejunal secretion, namely EPEC O55 (pa- tient 14) and EPEC O119 (patients 4 and 15). In the remaining 5 patients, bacteria of the colonic microflora, namely Proteus, Enterobacter, Pseudomonas and Klebsiella, were isolated from the jejunal secretion. In 3 of 8 patients without enteropathogens in the stool culture there was bacterial overgrowth in the jejunal secretion of the colonic type at concentrations above $10^{4}$ colonies $/ \mathrm{ml}$. In 5 patients no enteropathogenic bacteria were identified in the stool culture, and no bacterial overgrowth was observed in the jejunal fluid.

Morphological abnormalities of the small bowel mucosa were observed in all patients, varying in intensity from moderate to severe, when the semithin sections were analyzed by light microscopy; moderate villus atrophy was the most frequent pattern, confirmed in $9 / 16(56.3 \%)$ of the jejunal specimens. Subtotal villus atrophy was observed in 7 $(43.7 \%)$ patients and in 3 of them an entero-

Table 1 - Correlation between the presence of bacterial proliferation in the jejunal fluid and the presence of enteropathogenic agents in the stool culture with the morphological findings in the small bowel and in the rectal biopsies.

VA: Villus atrophy; SEM: scanning electron microscopy.

\begin{tabular}{|c|c|c|c|c|c|}
\hline Patients & $\begin{array}{l}\text { J ejunal juice } \\
\text { culture }\end{array}$ & Stool culture & $\begin{array}{l}\text { Small bowel } \\
\text { biopsy }\end{array}$ & $\begin{array}{l}\text { Rectal } \\
\text { biopsy }\end{array}$ & $\begin{array}{c}\text { Pseudomembrane } \\
\text { (SEM) }\end{array}$ \\
\hline 1 & E. coli & None & VA GIV & Normal & Absent \\
\hline 2 & E. coli & None & VA GIV & Normal & Absent \\
\hline 3 & Sterile & None & VA GII & Colitis & Absent \\
\hline 4 & EPEC 0119 & $\begin{array}{l}\text { EPEC 0119, } \\
\text { EAEC }\end{array}$ & VA GIII & Colitis & Present \\
\hline 5 & Sterile & None & VA GII & Colitis & Absent \\
\hline 6 & Pseudomonas & EPEC 0111 & VA GII & Normal & Present \\
\hline 7 & Sterile & None & VA GII & Normal & Absent \\
\hline 8 & Pseudomonas & EAEC & VA GII & Colitis & Present \\
\hline 9 & Enterobacter & Shigella & VA GII & Colitis & Present \\
\hline 10 & $\begin{array}{l}\text { Pseudomonas, } \\
\text { Enterobacter }\end{array}$ & None & VA GIII & Normal & Absent \\
\hline 11 & Proteus & $\begin{array}{l}\text { EPEC 0111, } \\
\text { EAEC }\end{array}$ & VA GII & Colitis & Present \\
\hline 12 & Sterile & None & VA GI & Colitis & Absent \\
\hline 13 & Klebsiella & EPEC 0111 & VA GII & Normal & Present \\
\hline 14 & EPEC O55 & $\begin{array}{l}\text { EPEC 055, } \\
\text { EPEC O111, } \\
\text { EAEC, Shigella }\end{array}$ & VA GIV & Colitis & Present \\
\hline 15 & EPEC 0119 & EPEC 0119 & VA GII & Colitis & Present \\
\hline 16 & Sterile & None & VA GII & Colitis & Absent \\
\hline
\end{tabular}


Figure 1 - Scanning electron microscopy of the jejunum of a patient with persistent diarrhea. Cells are not clearly visible except for some specific small areas (c) because they are covered with a mucus coating $(\mathrm{m})$. Cell borders are not recognizable in most of the epithelium (e). Lymphocytes (L) and fat droplets (f) are seen on the epithelial surface. Original magnification $=$ 2000X.

Figure 2 - A, Scanning electron microscopy of the jejunum of a patient with persistent diarrhea. The surface profiles of enterocytes (c) are flattened and covered with a mucus coating $(\mathrm{m})$ adhered to the microvillus surface. Original magnification $=$ 7500X. B, Scanning electron microscopy of the jejunum of a patient with persistent diarrhea. The microvillus surface $(\mathrm{m})$ is partly covered with a mucus-fibrinoid pseudomembrane (pm). Original magnification $=7500 \mathrm{X}$. pathogenic bacterium was isolated from the intestinal secretion and/or stools. Patchy areas of blunted microvilli were frequently seen associated with intracytoplasmic vacuolization. The inflammatory infiltrate, with lymphocytes, plasma cells and eosinophils in the lamina propria, was increased.

Colitis was seen in $10(62.5 \%)$ patients. In 6 of them, a relationship was established between the inflammatory lesion and the identification of an enteropathogenic agent
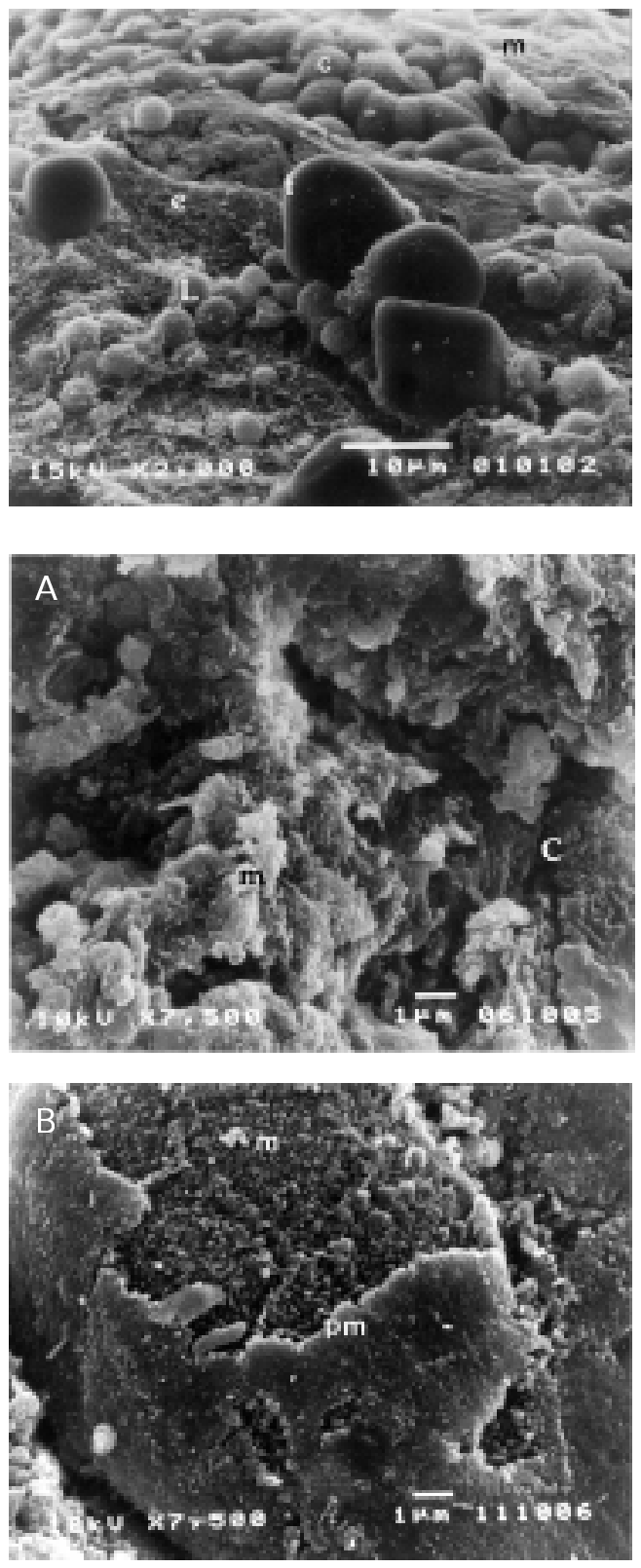

in the stools (Table 1).

Scanning electron microscopy examinations of the 16 patients revealed numerous abnormalities of the small bowel surface, although varying in intensity, in patients with bacterial proliferation in the jejunal fluid. At low magnification (150X) most of the villi showed mild to moderate stunting, but on several occasions there was subtotal villus atrophy. Villus ridges were not distinctly recognizable, showing subtotal atrophy, and vast areas of the villus surface were covered with mucus and debris, and the intervillus spaces were enlarged. At higher magnification $(7,500 \mathrm{X})$ photomicrographs showed derangement of the enterocytes; on several occasions cell borders were not clearly defined and very often microvilli were decreased in number and height; in some areas there was complete disappearance of the microvilli. Presence of lymphocytes and fat droplets overlying the surface of the enterocyte was noted in 3 patients (Figure 1). In half of the patients a mucus-fibrinoid pseudomembrane partially coating the enterocytes was observed (Figure 2A and B), and this finding presented a positive correlation with the presence of bacterial overgrowth in the small bowel (Table 1).

\section{Discussion}

In the present study we investigated two main parameters, i.e., the surface features and the presence of bacterial proliferation in the jejunal fluid. Scanning electron microscopy of biopsies of the jejunal mucosa provided additional information on the pathophysiology of persistent diarrhea.

The pathogenesis of persistent diarrhea is multifactorial and no single enteropathogenic agent could be identified as a predominant one in this clinical syndrome. Bacterial proliferation in the small bowel lumen in $68.7 \%$ of patients and high rates of isolation of enteropathogenic agents from the stools $(50.0 \%)$ may indicate that these microorgan- 
isms are significantly connected to the triggering of pathogenic mechanisms that perpetuate diarrhea. Our results are closely similar to the findings reported by Bardhan et al. (22) in Bangladesh, where bacterial overgrowth in the small bowel secretion was detected in $69 \%$ of patients and enteropathogenic agents were identified in $62 \%$ of patients suffering from persistent diarrhea. Since high counts of aerobic and anaerobic bacteria have been found in the jejunal secretion of infants with persistent diarrhea, it has been suggested that bacterial proliferation could be responsible for the perpetuation of diarrhea and nutrient malabsorption (23). In fact, bacterial overgrowth in the small bowel lumen may be responsible for several functional and morphological abnormalities such as deconjugation and $7 \alpha$ dehydroxylation of primary bile salts (24), sodium and water secretion (25), glucose malabsorption (26) and rupture of the intestinal permeability barrier favoring the penetration of intact macromolecules (27), and thus potentially leading to food allergy. Colitis was observed in 10 patients but an enteroinvasive microorganism was isolated from only 2 of them, and therefore food allergy might account for the remaining cases of colitis observed in our series.

We detected histological abnormalities of the small bowel mucosa in all infants; 9 had mild to moderate villus atrophy, and 7 had severe villus atrophy. Several investigators have suggested that villus atrophy in persistent diarrhea might be the result of an association of infection, food intolerance and malnutrition (28-30). Our results confirm these observations since our patients presented moderate to severe malnutrition and in most of them there was bacterial proliferation in the small intestine and/or an enteropathogenic agent was identified in the stool culture.

In the present study we were able to characterize severe derangements of the surface of the enterocyte, with the borders of the cells becoming not well defined. In several areas microvilli were completely denuded and on some occasions bacteria were also seen adhered to the apical portion of the enterocyte. These morphological alterations might be due to bacterial proliferation in the small bowel since this occurred in most patients.

The most striking overall finding of the present study was the presence of a mucusfibrinoid pseudomembrane overlying the intestinal surface in half of the specimens. The pseudomembrane was not associated with the presence of any particular microorganism, but was clearly associated with the occurrence of bacterial overgrowth in the small bowel. This finding is similar to that reported by Poley and Rosenfield (12) who studied infants with giardiasis and may be a nonspecific reaction of the intestinal mucosa against the presence of microorganisms overgrown in the intestinal lumen. The mucus coating may hamper absorption of dietary nutrients due to a mechanical block, thus leading to osmotic diarrhea and nutritional aggravation. This hypothesis is supported by the finding of fat droplets accumulated on the apical surface of the enterocytes in some of the patients studied. On the basis of these considerations, fat malabsorption could be explained by at least two different mechanisms: 1) a decrease in the bile salt pool as a consequence of bacterial proliferation resulting in deconjugation and $7 \alpha$ dehydroxylation of primary bile salts, and 2) presence of the mucus-fibrinoid pseudomembrane acting as a mechanical block avoiding the passage of dietary fat into the enterocytes.

The surface abnormalities of the small intestinal mucosa shown by the scanning electron microscopy in infants with persistent diarrhea, although nonspecific, are intense enough to justify the severity of the clinical aspects presented during a very early phase of life. A decrease in number and height of microvilli, blunting of enterocyte borders, loss of the glycocalyx, shortening of villi and presence of a mucus pseudomem- 
brane coating the mucosal surface were the abnormalities observed in the majority of the patients. These ultrastructural derangements may be due to an association of enteric enter- opathogenic agents that trigger the diarrheic process and the appearance of food intolerance responsible for perpetuation of the diarrhea.

\section{References}

1. WHO (1988). Persistent diarrhoea in children in developing countries: Memorandum from a WHO meeting. Bulletin of the World Health Organization, 66: 709-717.

2. Yoder S \& Hornik RC (1994). Perceptions of severity of diarrhoea and treatment choice: a comparative study of Healthy Com sites. J ournal of Tropical Medicine and Hygiene, 97: 1-12.

3. Bhutta ZA \& Hendricks KM (1996). Nutritional management of persistent diarrhea in childhood: a perspective from the developing world. J ournal of Pediatric Gastroenterology and Nutrition, 22: 17-37.

4. Lima AAM \& Guerrant RL (1992). Persistent diarrhea in children: Epidemiology, risk factors, pathophysiology, nutritional impact and management. Epidemiologic Reviews, 14: 222-242.

5. Bhandari N, Bhan MK, Sazawal S, Clemens J D, Bhatnagar $S \&$ Khoshoo V (1989). Association of antecedent malnutrition with persistent diarrhea: a casecontrol study. British Medical J ournal, 298: 1284-1287.

6. Fagundes-Neto $U$, Kallas MRE \& Patrício FRS (1997). Morphometric study of the small bowel mucosa in infants with diarrhea due to enteropathogenic Escherichia coli strains. Hepato-Gastroenterology, 44: 1051-1056.

7. Walker-Smith J A (1984). Food allergy and bowel disease in childhood. Midwife Health Visit Community Nurse, 20: 308316.

8. Sullivan PB \& Marsh MN (1992). Small intestinal mucosal histology in the syndrome of persistent diarrhoea and malnutrition: a review. Acta Paediatrica, 381 (Suppl): 72-77.

9. Fagundes-Neto U, Patrício FRS, WehbaJ , Reis MH, Gianotti OF \& Trabulsi LR (1979). An Escherichia coli strain that causes diarrhea by invasion of the small intestinal mucosa and induces monosaccharide intolerance. Arquivos de Gastroenterologia, 16: 205-208.

10. Fagundes-Neto U, Wehba J , Viaro T, Machado NL \& Patrício FRS (1985). Protracted diarrhea in infancy: clinical aspects and ultrastructural analysis of the small intestine. J ournal of Pediatric Gastroenterology and Nutrition, 4: 714-722.

11. Poley J R (1988). Loss of the glycocalyx of enterocytes in small intestine: a feature detected by scanning electron microscopy in children with gastrointestinal intolerance to dietary protein. J oumal of Pediatric Gastroenterology and Nutrition, 7: 386-394.

12. Poley J R \& Rosenfield S (1982). Malabsorption in giardiasis: presence of a luminal barrier (mucoid pseudomembrane). A scanning and transmission electron microscopic study. J ournal of Pediatric Gastroenterology and Nutrition, 1: 63-80.

13. Goméz F, Ramos RG \& Frenk S (1956). Mortality in second and third degree malnutrition. J ournal of Tropical Pediatrics, 2: 77-83.

14. National Center for Health Statistics (NCHS) (1977). Growth Curves for Children - 18 years. United States Department of Health Education and Welfare Vital and Health Statistics. Series II, NB, 165. HHEW Publication (PHS), Hysatesvalle, MD, 78-1650.

15. Edwards PR \& Ewing WH (1972). Identification of Enterobacteriacea. 3rd edn. Burgess Publishing Co., Minneapolis.

16. Ewing WH (1956). Enteropathogenic Escherichia coli serotypes. Annals of the New York Academy of Sciences, 66: 6167.

17. Nataro J P \& Kaper J B (1998). Diarrheagenic Escherichia coli. Clinical Microbiology Reviews, 11: 142-201.

18. Pereira HG, Azeredo RS, Leite JPG, Andrade ZP \& De Castro L (1985). A combined enzyme immunoassay for rotavirus and adenovirus (EIARA). J ournal of Virological Methods, 10: 21-28.

19. Toccalino H \& O'Donnell JC (1967). Tecnica para la introdución de la sondacapsula de Crosby en niños. Revista del Hospital de Niños de Buenos Aires, 12: 29-33.

20. Schenk EA \& Klipstein FA (1972). A protocol for the evaluation of small bowel biopsies. American J ournal of Clinical Nutrition, 25: 1108-1118.

21. Goldman H \& Proujansky R (1986). Aller- gic proctitis and gastroenteritis in children and mucosal biopsy features. American J ournal of Surgical Pathology, 10: 75-86.

22. Bardhan PK, Albert MJ , Alam NH, Faruque SM, Neogi PKB \& Mahalanabis D (1998). Small bowel and fecal microbiology in children suffering from persistent diarrhea in Bangladesh. J ournal of Pediatric Gastroenterology and Nutrition, 26: 9-15.

23. Bhatnagar S, Bhan MK, George C, Gupta U, Kumar R, Bright D \& Saini S (1992). Is small bowel bacterial overgrowth of pathogenic significance in persistent diarrhea? Acta Paediatrica, 381 (Suppl): 108-113.

24. Mathias J R \& Clench MH (1985). Pathophysiology of diarrhea caused by bacterial overgrowth of the small intestine. American J ournal of the Medical Sciences, 289: 243-248.

25. Fasano A, Verga MC, Raimondi $F$ \& Guandalini S (1994). Effects of deconjugated bile acids on electrolyte and nutrient transport in the rabbit small intestine in vitro. J ournal of Pediatric Gastroenterology and Nutrition, 18: 327-333.

26. Gracey $M$, Burke $V \& \&$ Anderson $C M$ (1969). Association of monosaccharide malabsorption with abnormal small intestinal flora. Lancet, 2: 384-385.

27. Fasano A, Budillon $G \&$ Guandalini $S$ (1990). Bile acids reversible effects on small intestinal permeability. Digestive Diseases and Sciences, 35: 801-808.

28. Fagundes-Neto U, Freymüller E, Schmitz LG \& Scaletsky I (1996). Nutritional impact and ultrastructural alterations due to enteropathogenic Escherichia coli strains in infants. J ournal of the American College of Nutrition, 15: 180-185.

29. Shiner M, Nichols VN, Barrish JP \& Nichols BL (1990). Pathogenesis of small intestinal mucosal lesions in chronic diarrhea of infancy: II - An electron microscopic study. J ournal of Pediatric Gastroenterology and Nutrition, 11: 464-480.

30. Sullivan $\mathrm{PB}, \mathrm{Marsh} M N \&$ Mirakian $R$ (1992). Chronic diarrhea and malnutrition histology of the small intestinal lesion. J ournal of Pediatric Gastroenterology and Nutrition, 14: 371-379. 